\title{
Desert dust aerosol air mass mapping in the western Sahara, using particle properties derived from space-based multi-angle imaging
}

\author{
By RALPH KAHN ${ }^{1 *}$, ANDREAS PETZOLD ${ }^{2}$, MANFRED WENDISCH $^{3}$, EIKE BIERWIRTH ${ }^{3}$, \\ TILMAN DINTER ${ }^{4}$, MICHAEL ESSELBORN ${ }^{2}$, MARCUS FIEB IG ${ }^{5}$, B IRGIT HEESE ${ }^{6}$, \\ PETER KNIPPERTZ ${ }^{3}$, DETLEF MÜLLER ${ }^{6}$, ALEX ANDER SCHLADITZ ${ }^{6}$ \\ and W OLFGA NG VON HOY NIN GEN-HUENE ${ }^{4},{ }^{1}$ NASA Goddard Space Flight Center, Greenbelt, MD \\ 20771, USA; ${ }^{2}$ Institute for Atmospheric Physics, German Aerospace Center (DLR), Wessling, Germany; ${ }^{3}$ Institute for \\ Atmospheric Physics, Johannes Gutenberg-University Mainz, Germany; ${ }^{4}$ Institute of Environmental Physics, \\ University of Bremen, Germany; ${ }^{5}$ Department of Atmospheric and Climate Research, Norwegian Institute for Air \\ Research, Kjeller, Norway; ${ }^{6}$ Leibniz Institute for Tropospheric Research, Leipzig, Germany
}

(Manuscript received 24 March 2008; in final form 18 September 2008)

\begin{abstract}
Coincident observations made over the Moroccan desert during the Sahara mineral dust experiment (SAMUM) 2006 field campaign are used both to validate aerosol amount and type retrieved from multi-angle imaging spectroradiometer (MISR) observations, and to place the suborbital aerosol measurements into the satellite's larger regional context. On three moderately dusty days during which coincident observations were made, MISR mid-visible aerosol optical thickness (AOT) agrees with field measurements point-by-point to within $0.05-0.1$. This is about as well as can be expected given spatial sampling differences; the space-based observations capture AOT trends and variability over an extended region. The field data also validate MISR's ability to distinguish and to map aerosol air masses, from the combination of retrieved constraints on particle size, shape and single-scattering albedo. For the three study days, the satellite observations (1) highlight regional gradients in the mix of dust and background spherical particles, (2) identify a dust plume most likely part of a density flow and (3) show an aerosol air mass containing a higher proportion of small, spherical particles than the surroundings, that appears to be aerosol pollution transported from several thousand kilometres away.
\end{abstract}

\section{Introduction}

Satellite instruments such as the multi-angle imaging spectroradiometer (MISR) routinely produce global maps reporting aerosol amount and type. However, much remains to be learned about the accuracy of these products, and about how they can be used for regional studies that require the extensive coverage satellites provide, along with a level-of-detail obtainable only from suborbital platforms.

During the Sahara mineral dust experiment (SAMUM) in May and June 2006 (Heintzenberg et al., 2008), coincident surface, airborne and satellite measurements of the nearly pure dust aerosol in the skies around Ouarzazate and Zagora, Morocco

\footnotetext{
* Corresponding author.

e-mail: ralph.kahn@nasa.gov

DOI: $10.1111 /$ j.1600-0889.2008.00398.x
}

were collected. This region, at the western edge of Saharan dust sources, was targeted due to the trans-continental environmental impact these aerosols have, an observation first made at the advent of the satellite era (e.g. Prospero et al., 1981).

The MISR team participated actively in SAMUM field operations; this paper provides a summary of our initial scientific results. The multi-angle imaging spectroradiometer, which flies aboard the NASA Earth Observing System's Terra satellite (http://www-misr.jpl.nasa.gov), is especially well suited to study aerosols in the desert environment on $10-100 \mathrm{~km}$ scales. The multi-angle imaging spectroradiometer makes nearsimultaneous measurements at nine view-angles spread out in the forward and aft directions along the flight path, at $\pm 70.5^{\circ}$, $\pm 60.0^{\circ}, \pm 45.6^{\circ}, \pm 26.1^{\circ}$, and nadir, in each of four spectral bands centred at 446, 558, 672 and $866 \mathrm{~nm}$ (Diner et al., 1998).

With these observations, the instrument systematically covers a range of air mass factors (slant paths through the atmosphere) 
from one (for nadir viewing) to three (for the steepest angle), providing greater sensitivity to aerosol optical thickness (AOT) than single-view measurements, over land in general (Abdou et al., 2005; Kahn et al., 2005) and especially over bright surfaces such as desert (Martonchik et al., 2004). In mid-latitudes, MISR samples scattering angles extending from about $60^{\circ}$ to $160^{\circ}$, making it possible to distinguish spherical particles, such as aerosol pollution, from non-spherical desert dust (Kalashnikova and Kahn, 2006; Kahn et al., 1997), and to derive some information about particle size and single-scattering albedo (SSA;Kahn et al., 1998; Chen et al., 2008). Note that the MISR spectral range provides sensitivity to particle properties for aerosol up to about $2.5 \mu \mathrm{m}$ in diameter $\left(\mathrm{PM}_{2.5}\right)$, but is insensitive to the properties of larger particles, which is a limitation in desert applications, especially near sources. The multi-angle imaging spectroradiometer views nearly the entire Earth about once per week, with spatial sampling of $275 \mathrm{~m}$ to $1.1 \mathrm{~km}$, depending on channel and instrument operating mode. The MISR standard aerosol product is reported over $17.6 \mathrm{~km}$ regions (Martonchik et al., 1998, 2002).

The primary motivations for MISR team participation in SAMUM are (a) to quantify MISR's ability to retrieve AOT and mineral dust properties over bright desert surfaces and (b) to contribute to the campaign data set MISR regional AOT and aerosol air mass type maps. The maps provide context for the more detailed but less extensive measurements made by the aircraft and ground-based platforms. We present here both initial validation results and regional maps for three Golden Days, days during which aircraft and surface data were acquired coincident with the MISR overpasses: 19 May, 28 May and 4 June 2006. These days happen to fall within each of the three SAMUM dusty periods identified with aircraft data (Petzold et al., 2008). At the Tinfou surface station near Zagora, high dust concentrations were recorded on 19 and 28 May (Schladitz et al., 2008), and on 4 June, dust-laden density current outflows were documented in Meteosat images and surface meteorological station data (Knippertz et al., 2007).

The following sections report the MISR observations on each day, present maps of retrieved AOT and particle properties and offer a preliminary assessment of MISR standard aerosol retrieval results in light of near-coincident field data. A summary and conclusions are provided at the end.

\section{Aerosol air mass analyses}

We begin with a brief review of the aerosol amount and property constraints produced by MISR over the study region, comparing values and trends with near-simultaneous field data acquired during SAMUM. This summary reveals the contributions both the satellite and suborbital data make to environmental characterization. Although MISR did not image a major dust storm (many tens of kilometres in size) during this campaign, mid-visible AOT $>\sim 0.5$ from regional dust storms as well as gradients of airborne dust and spherical background particles were observed at $\sim 10$ to $\sim 100 \mathrm{~km}$ scales on all 3 days.

\subsection{May 2006}

This section presents results for the first of three Golden Days. It includes a summary of particle properties derived from aircraft and surface observations that are used to compare with MISRretrieved values in subsequent sections as well.

2.1.1. Retrieved aerosol amount and type patterns. Figure 1 gives a point-to-point comparison between MISR and surfaceretrieved AOT at the Ouarzazate and Tinfou study sites on 19 May 2006 (Unless stated otherwise, AOT is reported in this paper for the MISR green band, at an effective wavelength of $558 \mathrm{~nm}$ ). The multi-angle imaging spectroradiometer standard aerosol mid-visible AOT retrievals at $17.6 \mathrm{~km}$ spatial resolution in the vicinity of Ouarzazate were clustered between 0.35 and 0.45. The AERONET retrievals (Holben et al., 1998) show AOT in this spectral range increasing from about 0.36 to 0.43 over the morning hours leading up to the overpass, and levelling off at about 0.45 shortly thereafter. Allowing for sampling differences between the MISR $17.6 \mathrm{~km}$ retrieval region and the sun photometer point measurements, convolved with the envelope of spatial and temporal AOT variations observed in the MISR and sun photometer data, respectively, this amounts to close agreement between the two measurements (e.g. Kahn et al., 2005). Similarly, the sun photometer at Tinfou registered mid-visible AOTs within the range of values retrieved by MISR in the vicinity of that site.

A comprehensive view of AOT and optical properties for the MISR overpass is given in Fig. 2. The MISR retrievals illustrated in Fig. 2a show greater AOT spatial variability in the immediate surroundings of Tinfou than at Ouarzazate, and corresponding temporal variability is observed as occasional peaks in the Tinfou sun photometer AOT time-series (Fig. 1c). The observations show a consistent envelope of MISR AOT values encompassing the range observed from the surface, suggesting that local dust sources may have been active during the late morning. This interpretation is supported by local meteorological conditions. 19 May was a day on which the mean wind speed was fairly low, but dry convective dust plume activity that could cause this small-scale variability was reported at Ouarzazate some time between 10:00 and 12:00 UTC (see Ansmann et al., 2008, fig. 9). The 11:11 UTC MISR overpass time might have occurred near the start of local plume activity.

Another view of AOT in the study area is provided by the high-spectral-resolution lidar (HSRL) aboard the Falcon F20E aircraft (Esselborn et al., 2008a,b). The relevant aircraft trajectory is plotted as a dashed red line in Fig. 2a (see also Esselborn et al., 2008b, fig. 3a). A detailed comparison between AOT derived from MISR and HSRL along this trajectory as well as the Ouarzazate sun photometer value is shown in Fig. 1d. For this comparison, the four $17.6 \mathrm{~km}$ MISR retrieval regions 

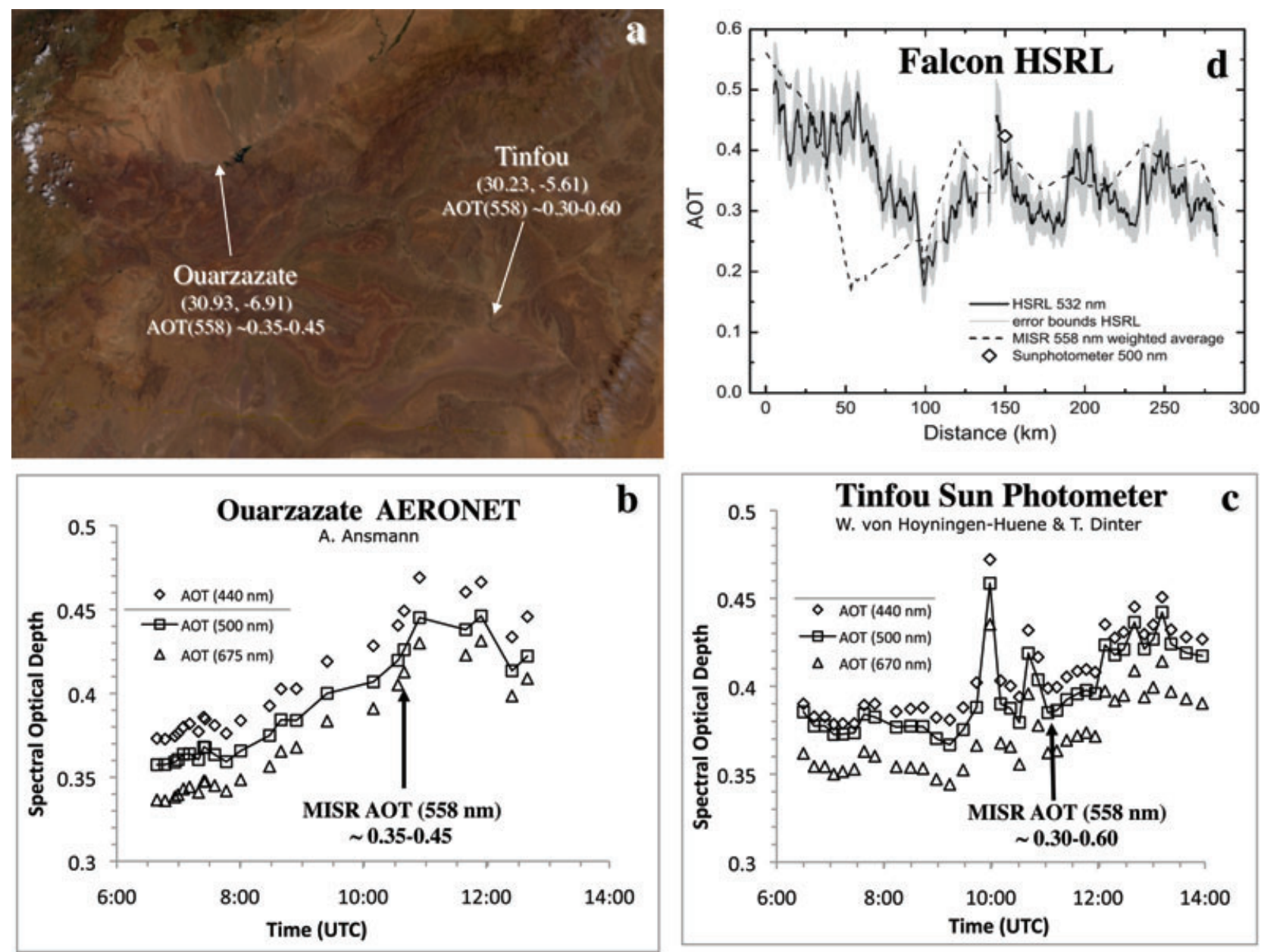

Fig. 1. The 19 May 2006 SAMUM event, Orbit 34136, Path 201. (a) Multi-angle imaging spectroradiometer true-colour nadir image of the Ouarzazate and Tinfou study sites and surrounding areas. The latitudes, longitudes and MISR standard product $558 \mathrm{~nm}$ AOT (Version 19) at the study sites are given in the image annotation. The swath is approximately $400 \mathrm{~km}$ wide. Surface-based sun photometer multispectral AOT time-series at (b) Ouarzazate (Ansmann et al., 2008) and (c) Tinfou (Dinter et al., 2008; von Hoyningen-Huene et al., 2008). The sun photometer green-band AOT at MISR overpass time (11:11 UTC) is indicated with an arrow. (d) Near-coincident, mid-visible AOT derived from the Falcon airborne high-spectral-resolution lidar (HSRL) on Research Flight (RF) 1 from Esselborn et al. (2008b, fig. 8a), along a trajectory marked approximately as a dashed red line in Fig. 2a, with the spatially correlated MISR AOT and Ouarzazate sun photometer AOT superposed.

neighbouring the narrow HSRL sampling footprint (averaged along-track to $3.0 \mathrm{~km}$ lateral resolution) were interpolated bilinearly to the HSRL measurement location. As with the surface sun photometers, co-registration uncertainties and differences in sampling size can easily account for most of the observed differences, except for approximately $50 \mathrm{~km}$ along the Falcon trajectory (Fig. 1d), which was taken early in the flight, north and east of the Ouarzazate station, in the complex terrain of the High Atlas mountains. In situations where the surface elevation varies substantially on short spatial scales, assumptions in the MISR retrieval algorithm about a uniform atmospheric column can be violated. Also, sampling differences between the lidar and MISR are exacerbated under these conditions.

Returning to the larger view, mid-visible AOT increases from between 0.4 and 0.5 in the prime study region to over 1.0 about
$350 \mathrm{~km}$ to the SSW (Fig. 2a). Panels b-d of Fig. 2 show the retrieved Angström exponent [defined as the negative slope of a least-squares fit to $\log$ (AOT) vs. $\log$ (wavelength)], SSA, and fraction AOT spherical (which is the fraction of the total column mid-visible AOT that the algorithm did not assign to non-spherical dust components). These particle microphysical properties all diminish as AOT increases on the regional scale, suggesting larger, non-spherical, dust-like particles are more abundant as AOT increases. In particular, the dust contribution to mid-visible AOT increases from about $40 \%$ to as much as $70 \%$, as the total column AOT increases.

HYSPLIT backtrajectories (Draxler and Rolph, 2003) for Ouarzazate and Tinfou indicate that the entire region was under the influence of a high-pressure system centred over northcentral Algeria, causing air at all levels to sweep across central 

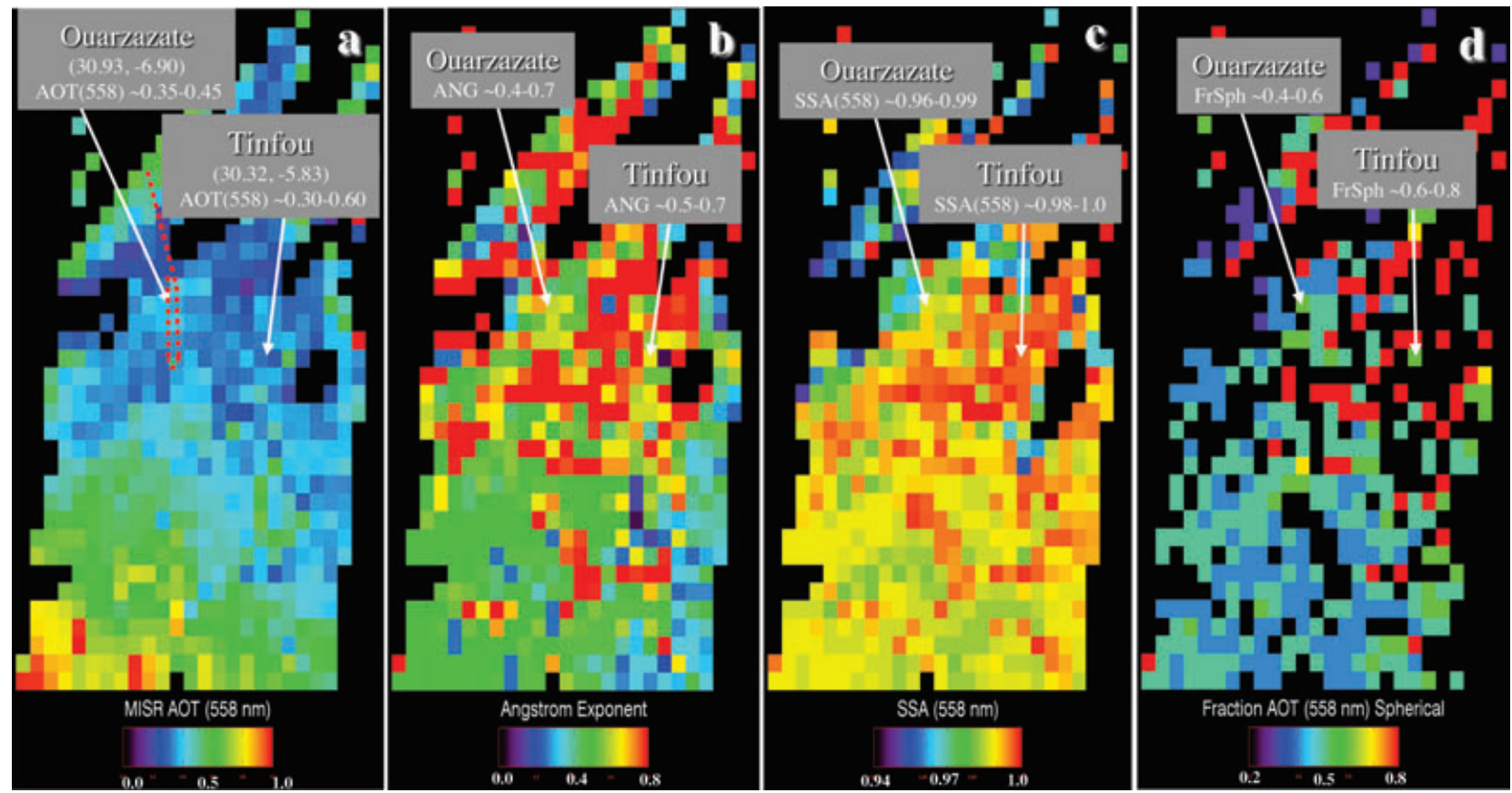

Fig. 2. Multi-angle imaging spectroradiometer standard aerosol product (Version 19) results for the 19 May 2006 SAMUM event. (a) AOT at $558 \mathrm{~nm}$. (b) Ångström exponent, assessed by least-squared fit to the four MISR spectral bands that range from 446 to $867 \mathrm{~nm}$. (c) Aerosol single-scattering albedo (SSA), assessed at $558 \mathrm{~nm}$. (d) Fraction of $558 \mathrm{~nm}$ AOT retrieved as spherical particles. The region is about $380 \mathrm{~km}$ wide, and approximately $700 \mathrm{~km}$ along-track (MISR Blocks 64-68 of the standard product). The trajectory of the Falcon HSRL is marked approximately as a dashed red line in part (a).

Algeria from east to west, arriving at the study sites from the ESE (not shown, but similar to the situation $2 \mathrm{~d}$ earlier given in Knippertz et al., 2008, fig. 3b). This picture is consistent with the fairly uniform aerosol air mass derived by MISR for the $\sim 200 \mathrm{~km} \mathrm{~N}-\mathrm{S}$ region that includes the study sites themselves. Further, animations of the Meteosat Second Generation (MSG) dust product (Schepanski et al., 2007) suggest that the higher regional AOT observed this day over western Algeria by MISR originated primarily from two local sources near the western edge of the Tademaït Plateau on 18 May (see Heinold et al., 2008, fig. 1h).

\subsubsection{Particle microphysical property validation}

2.1.2.1. Field measurement summary. The Sahara mineral dust experiment field measurements included aircraft and groundbased aerosol and surface optical property measurements on all three MISR Golden Days. These measurements are described in detail in companion papers referenced below; we use them as 'ground truth' against which to compare with MISR particle property retrieval results. Generally, the field measurements detected two components: medium sized, non-spherical, relatively bright dust and small, spherical, more absorbing background particles, which may be transported aerosol pollution or smoke, in varying proportions.

Specifically, near-surface aerosol optical property observations made at Tinfou found a coarse mode component having a number-weighted median diameter of about $0.6 \mu \mathrm{m}$ and a volume-weighted median diameter between 2 and $3 \mu \mathrm{m}$, for periods covering both the 19 and 28 May MISR events (Schladitz et al., 2008). This component was associated with mineral dust. On 27-28 May, when dust dominated the aerosol load, the SSA was about $0.96 \pm 0.02$ at $530 \mathrm{~nm}$ and $0.98 \pm 0.01$ at $630 \mathrm{~nm}$ wavelengths. A spherical fine mode, having median numberweighted diameter around $0.07-0.09 \mu \mathrm{m}$ was also detected. On 29-30 May, when this component contributed a larger fraction to the total optical depth than on other days (though there were no coincident MISR observations), the effective SSA was about $0.91 \pm 0.02$ at $530 \mathrm{~nm}$ and $0.93 \pm 0.01$ at $630 \mathrm{~nm}$ wavelengths (Schladitz et al., 2008).

Similar conclusions about particle sizes, and the relative abundance of coarse and fine mode, were reached based on airborne measurements of aerosol layers between about 1.5 and $5 \mathrm{~km}$ above sea level (a.s.1.) for the entire campaign, but unlike the surface observations, mid-visible SSA values below 0.8 were recorded from the aircraft (Otto et al., 2008; Petzold et al., 2008). These values are quite low for aged aerosols, but their difference compared to the surface measurements may be explained as follows: initially low-SSA transported aerosol pollution may have been concentrated in isolated layers aloft. Otto et al. (2008, fig. 3c) find the relative humidity (RH) at these elevations was below $45 \%$ from radiosonde measurements, nearly coincident with the MISR overpass on 19 May. If RH in the aerosol layers remained low during transport, hydration and chemical ageing, 

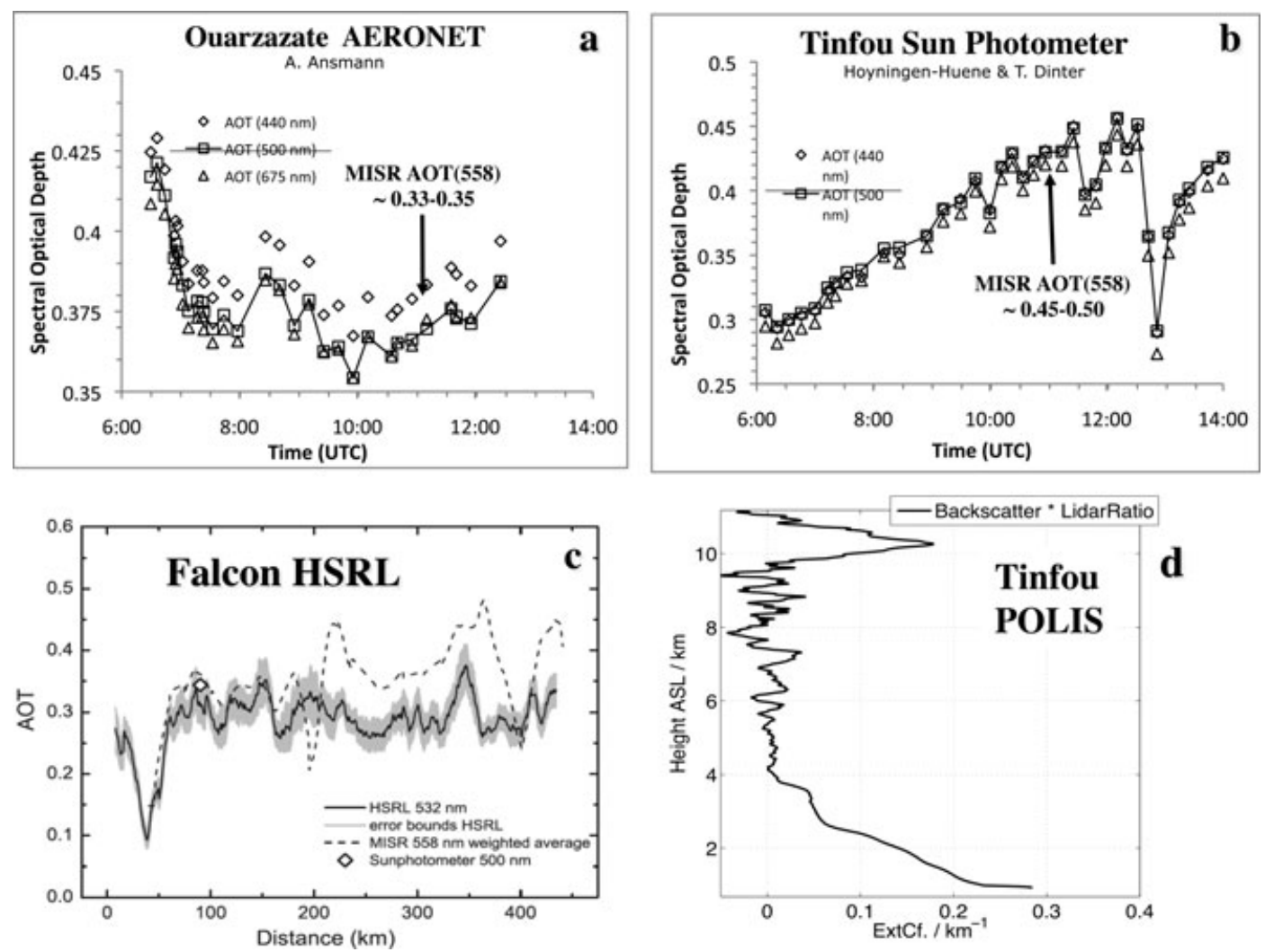

Fig. 3. The 28 May 2006 SAMUM event, Orbit 34267, Path 200. Surface-based sun photometer multispectral AOT time-series at (a) Ouarzazate and (b) Tinfou. The sun photometer green-band AOT at MISR overpass time (11:05 UTC) is indicated with an arrow. (c) Near-coincident, mid-visible AOT derived from the Falcon HSRL on RF-5, along a trajectory marked approximately as a dashed red line in Fig. 4a, with the spatially correlated MISR AOT and Ouarzazate sun photometer AOT superposed. (d) Vertical profile of extinction coefficient at Tinfou, between 11:30 and 11:45 UTC, derived from the POLIS surface-based lidar backscatter, assuming a lidar ratio of $20 \mathrm{sr}$ in the cirrus region above $9 \mathrm{~km}$ a.s.l., and $55 \mathrm{sr}$ elsewhere.

processes that dominate aerosol evolution in more humid environments, may not be effective at increasing particle SSA here.

From the aggregate of field observations, described in the references cited above, including particle indices of refraction, size distributions, size distribution discrepancies among different measurement techniques, hygroscopicity and composition, it was also deduced that the component size distributions and coarse-mode microphysical properties were fairly stable over the entire SAMUM measurement period. Schladitz et al. (2008) identify, as the optical analogue for their coarse mode particles at Tinfou, the weakly absorbing grains modelled by Kalashnikova et al. (2005) and used in the standard MISR aerosol retrieval algorithm as 'medium grains' (Table 1).

2.1.2.2. MISR standard algorithm particle property comparison. The MISR algorithm uses a set of absolute criteria to decide which aerosol mixtures, from a fixed list of candidate mixtures that is applied globally, provide acceptable matches to the observed radiances (Martonchik et al., 1998, 2002; Kahn et al., 2001). Multiple mixtures may pass the acceptance tests, and the range of properties gives some indication of the constraints provided by the MISR radiances. For the standard algorithm version
Table 1. Multi-angle imaging spectroradiometer standard aerosol retrieval algorithm (Version 19)

\begin{tabular}{ll}
\hline Component & Name/description \\
\hline 1 & Spherical_non-absorbing_0.06 \\
2 & Spherical_non-absorbing_0.12 \\
3 & Spherical_non-absorbing_0.26 \\
6 & Spherical_non-absorbing_2.80 \\
8 & Spherical_absorbing_0.12_ssa_green_0.9 \\
14 & Spherical_absorbing_0.12_ssa_green_0.8 \\
19 & Medium_grains ${ }^{\mathrm{a}}$ \\
21 & Coarse_spheroids $^{\mathrm{a}}$ \\
\hline
\end{tabular}

Note: Aerosol components are named based on particle shape (spherical, non-spherical grains or spheroids), SSA (non-absorbing or absorbing) and number-weighted mean geometric radius (in $\mu \mathrm{m}$ ). For absorbing aerosols, the green-band SSA is also given. This table lists the eight components used in Table 2.

${ }^{\mathrm{a}} \mathrm{A}$ full description of the dust particle optical analogues used in the MISR standard algorithm is given by Kalashnikova et al. (2005). 
used here (V19), this list contains 74 mixtures (Table 2), comprised of up to three of the eight components given in Table 1. There are three groupings of bi-modal, spherical, non-absorbing particles; each group has a coarse mode of number-weighted mean geometric radius $2.80 \mu \mathrm{m}$, combined with a fine mode of radius $0.06,0.12$ or $0.26 \mu \mathrm{m}$, in 10 increments of varying proportions. These are followed in Table 2 by two groups of 10 mixtures each, for which the fine mode is an absorbing, spherical particle of radius 0.12 , having mid-visible SSA 0.90 and 0.80 , respectively. The remaining 24 mixtures are bi- and tri-modal distributions that include medium or medium + coarse-mode dust analogues.

On 19 May, for retrieval regions surrounding the Ouarzazate surface station, the MISR algorithm preferentially selected mixtures containing about $60 \%$ mid-visible optical depth dust (e.g. Mixtures 58, 63 and 64 in Table 2). The second component is primarily medium, spherical, non-absorbing particles, an outcome consistent with field measurements. This result provides sufficient detail to identify aerosol air mass type: dust, plus a fine-mode spherical component in these proportions. However, looking in more detail at particle size and SSA, the retrieved spherical component, having number-weighted mean geometric radius of $0.12 \mu \mathrm{m}$, is both less absorbing and significantly larger than the spherical fine mode observed in the field. But note that the $0.12 \mu \mathrm{m}$ particle is the only small-medium spherical component in mixtures containing both spherical and nonspherical particles allowed by the MISR Version 19 standard algorithm (Table 2). For fixed AOT, larger particles having the same SSA scatter less light (smaller scattering cross-section per unit AOT), so to some extent the MISR algorithm may substitute larger, brighter particles for the smaller, darker ones observed in situ, still obtain very good AOT agreement and still preserve the mixed spherical + non-spherical aerosol air mass category (This non-uniqueness of MISR aerosol property information is explored in detail in previous papers, such as Chen et al., 2008; Kalashnikova and Kahn, 2006 and references therein).

At most locations in the vicinity of Ouarzazate, on this relatively high AOT day, the MISR algorithm accepted no more than two or three dust-containing mixtures, as described above. In a few places, other mixtures that met the acceptance criteria, though not the lowest-residual (best fitting) mixtures, contain up to $30 \%$ of the very large, spherical, non-absorbing particles (Mixtures 52 and 55 in Table 2). Here, the algorithm may be substituting large spherical particles for a super- $\mu \mathrm{m}$ mineral dust component, since the available optical analogue (Particle 21 in Table 1), derived using a spheroidal approximation, may not adequately represent the natural particles (see Kalashnikova et al., 2005).

There are also several sites at which eight or more mixtures passed the algorithm acceptance criteria, including some containing only medium spherical particles. When so many mixtures having different microphysical properties are retrieved, it is an indication that the particle property retrieval itself is not well constrained. If this occurs because the total column AOT is low, the AOT retrieval does not depend heavily on particle properties, and may still be robust (Kahn et al., 1998, 2005). Other possible causes, likely in this case, are inadequate surface or aerosol optical models, or varying aerosol amount or properties within the retrieval region; these contingencies violate fundamental assumptions of the algorithm. Multi-angle imaging spectroradiometer results for Tinfou are similar, with dust + a fine-mode spherical component comprising the lowest-residual mixtures selected, though there are more cases where multiple mixtures of varying properties pass, most likely reflecting the greater small-scale aerosol loading variability seen in Fig. 2.

In summary, within the limitations of the algorithm mixture table, the MISR retrievals found bi-modal distributions containing significant dust, combined with a fine-mode spherical component in rough agreement with field observations, and adequate to distinguish aerosol air mass types. However, a lack of mixtures containing small, spherical, absorbing particles combined with dust, and suspected limitations of the optical model used for super- $\mu \mathrm{m}$ sized mineral dust, limit the degree to which the satellite-derived particle properties could match those observed directly (e.g. Kalashnikova and Kahn, 2006; Chen et al., 2008). One reason for performing particle property field validation is to identify limitations in the current standard algorithm, such as those found here. The MISR research aerosol retrieval algorithm, with which a vastly wider range of aerosol components and mixtures can be explored than with the standard algorithm, is the key tool for such investigations (Kahn et al., 2001; Kalashnikova and Kahn, 2006; Chen et al., 2008). This is beyond the scope of the current paper, but is the subject of continuing work aimed at refining the standard algorithm component and mixture tables, and quantifying the sensitivity of the upgraded algorithm.

\subsection{May 2006}

Point-to-point comparisons of mid-visible AOT at the prime study sites for the 28 May event are given in Fig. 3. On this day there is a definite gradient, reflected in both the satellite and surface measurements, with AOT 0.1-0.15 higher at Tinfou than Ouarzazate at MISR overpass time. This gradient appears in larger context in the MISR regional AOT and particle property maps of Fig. 4, and near-coincident Falcon HSRL observations provide further, quantitative validation. The aircraft track is superposed on Fig. 4a, and the HSRL AOT is plotted along with bi-lineraly interpolated MISR AOT in Fig. 3c. As occurred on 19 May, AOT agreement is within uncertainties here, except beyond $200 \mathrm{~km}$ along the Falcon flight track. The observations in the anomalous segment were taken over thin cirrus south of Tinfou, possibly associated with thicker clouds visible in MISR images, which also contribute to the lack of aerosol retrievals in the southern part of the swath. Surface-based POLIS depolarization lidar measurements at Tinfou (B. Heese, personal communication, 2008) confirm the presence of very thin cirrus 
Table 2. Multi-angle imaging spectroradiometer standard algorithm (Version 19) aerosol mixtures

\begin{tabular}{|c|c|c|c|c|c|c|c|c|c|c|c|c|c|c|c|}
\hline \multirow[t]{2}{*}{ Mixture } & \multicolumn{8}{|c|}{ Component fractional AOT (at $558 \mathrm{~nm}$ ) } & \multicolumn{3}{|c|}{ AOT rel. to green } & \multicolumn{4}{|c|}{ single-scattering albedo } \\
\hline & $1^{\mathrm{a}}$ & $2^{\mathrm{a}}$ & $3^{\mathrm{a}}$ & $6^{\mathrm{a}}$ & $8^{\mathrm{a}}$ & 14 & $19^{\mathrm{a}}$ & $21^{\mathrm{a}}$ & Blue & Red & Nir & Blue & Green & Red & Nir \\
\hline 1 & 1 & - & - & - & - & - & - & - & 1.95 & 0.549 & 0.23 & 1 & 1 & 1 & 1 \\
\hline 2 & 0.95 & - & - & 0.05 & - & - & - & - & 1.9 & 0.573 & 0.271 & 1 & 1 & 1 & 1 \\
\hline 3 & 0.9 & - & - & 0.1 & - & - & - & - & 1.85 & 0.596 & 0.312 & 1 & 1 & 1 & 1 \\
\hline 4 & 0.8 & - & - & 0.2 & - & - & - & - & 1.76 & 0.644 & 0.395 & 1 & 1 & 1 & 1 \\
\hline 5 & 0.7 & - & - & 0.3 & - & - & - & - & 1.66 & 0.691 & 0.477 & 1 & 1 & 1 & 1 \\
\hline 6 & 0.6 & - & - & 0.4 & - & - & - & - & 1.57 & 0.738 & 0.559 & 1 & 1 & 1 & 1 \\
\hline 7 & 0.5 & - & - & 0.5 & - & - & - & - & 1.47 & 0.786 & 0.642 & 1 & 1 & 1 & 1 \\
\hline 8 & 0.4 & - & - & 0.6 & - & - & - & - & 1.37 & 0.833 & 0.724 & 1 & 1 & 1 & 1 \\
\hline 9 & 0.3 & - & - & 0.7 & - & - & - & - & 1.28 & 0.881 & 0.807 & 1 & 1 & 1 & 1 \\
\hline 10 & 0.2 & - & - & 0.8 & - & - & - & - & 1.18 & 0.928 & 0.889 & 1 & 1 & 1 & 1 \\
\hline 11 & - & 1 & - & - & - & - & - & - & 1.54 & 0.66 & 0.348 & 1 & 1 & 1 & 1 \\
\hline 12 & - & 0.95 & - & 0.05 & - & - & - & - & 1.51 & 0.679 & 0.384 & 1 & 1 & 1 & 1 \\
\hline 13 & - & 0.9 & - & 0.1 & - & - & - & - & 1.49 & 0.697 & 0.419 & 1 & 1 & 1 & 1 \\
\hline 14 & - & 0.8 & - & 0.2 & - & - & - & - & 1.43 & 0.733 & 0.49 & 1 & 1 & 1 & 1 \\
\hline 15 & - & 0.7 & - & 0.3 & - & - & - & - & 1.38 & 0.769 & 0.56 & 1 & 1 & 1 & 1 \\
\hline 16 & - & 0.6 & - & 0.4 & - & - & - & - & 1.32 & 0.805 & 0.631 & 1 & 1 & 1 & 1 \\
\hline 17 & - & 0.5 & - & 0.5 & - & - & - & - & 1.26 & 0.842 & 0.701 & 1 & 1 & 1 & 1 \\
\hline 18 & - & 0.4 & - & 0.6 & - & - & - & - & 1.21 & 0.878 & 0.772 & 1 & 1 & 1 & 1 \\
\hline 19 & - & 0.3 & - & 0.7 & - & - & - & - & 1.15 & 0.914 & 0.843 & 1 & 1 & 1 & 1 \\
\hline 20 & - & 0.2 & - & 0.8 & - & - & - & - & 1.1 & 0.95 & 0.913 & 1 & 1 & 1 & 1 \\
\hline 21 & - & - & 1 & - & - & - & - & - & 1.18 & 0.82 & 0.576 & 1 & 1 & 1 & 1 \\
\hline 22 & - & - & 0.95 & 0.05 & - & - & - & - & 1.17 & 0.83 & 0.6 & 1 & 1 & 1 & 1 \\
\hline 23 & - & - & 0.9 & 0.1 & - & - & - & - & 1.17 & 0.841 & 0.624 & 1 & 1 & 1 & 1 \\
\hline 24 & - & - & 0.8 & 0.2 & - & - & - & - & 1.15 & 0.861 & 0.672 & 1 & 1 & 1 & 1 \\
\hline 25 & - & - & 0.7 & 0.3 & - & - & - & - & 1.13 & 0.881 & 0.72 & 1 & 1 & 1 & 1 \\
\hline 26 & - & - & 0.6 & 0.4 & - & - & - & - & 1.11 & 0.901 & 0.767 & 1 & 1 & 1 & 1 \\
\hline 27 & - & - & 0.5 & 0.5 & - & - & - & - & 1.09 & 0.921 & 0.815 & 1 & 1 & 1 & 1 \\
\hline 28 & - & - & 0.4 & 0.6 & - & - & - & - & 1.07 & 0.942 & 0.863 & 1 & 1 & 1 & 1 \\
\hline 29 & - & - & 0.3 & 0.7 & - & - & - & - & 1.05 & 0.962 & 0.911 & 1 & 1 & 1 & 1 \\
\hline 30 & - & - & 0.2 & 0.8 & - & - & - & - & 1.03 & 0.982 & 0.959 & 1 & 1 & 1 & 1 \\
\hline 31 & - & - & - & - & 1 & - & - & - & 1.51 & 0.677 & 0.375 & 0.911 & 0.9 & 0.885 & 0.8 \\
\hline 32 & - & - & - & 0.05 & 0.95 & - & - & - & 1.48 & 0.694 & 0.409 & 0.914 & 0.905 & 0.894 & 0.8 \\
\hline 33 & - & - & - & 0.1 & 0.9 & - & - & - & 1.45 & 0.712 & 0.443 & 0.917 & 0.91 & 0.902 & 0.8 \\
\hline 34 & - & - & - & 0.2 & 0.8 & - & - & - & 1.4 & 0.746 & 0.511 & 0.924 & 0.92 & 0.917 & 0.9 \\
\hline 35 & - & - & - & 0.3 & 0.7 & - & - & - & 1.35 & 0.781 & 0.578 & 0.931 & 0.93 & 0.93 & 0.9 \\
\hline 36 & - & - & - & 0.4 & 0.6 & - & - & - & 1.3 & 0.815 & 0.646 & 0.938 & 0.94 & 0.943 & 0.9 \\
\hline 37 & - & - & - & 0.5 & 0.5 & - & - & - & 1.25 & 0.85 & 0.714 & 0.946 & 0.95 & 0.954 & 0.9 \\
\hline 38 & - & - & - & 0.6 & 0.4 & - & - & - & 1.2 & 0.884 & 0.782 & 0.955 & 0.96 & 0.965 & 0.9 \\
\hline 39 & - & - & - & 0.7 & 0.3 & - & - & - & 1.14 & 0.919 & 0.85 & 0.965 & 0.97 & 0.975 & 0.9 \\
\hline 40 & - & - & - & 0.8 & 0.2 & - & - & - & 1.09 & 0.953 & 0.918 & 0.976 & 0.98 & 0.984 & 0.9 \\
\hline 41 & - & - & - & - & - & 1 & - & - & 1.47 & 0.695 & 0.403 & 0.821 & 0.8 & 0.773 & 0.7 \\
\hline 42 & - & - & - & 0.05 & - & 0.95 & - & - & 1.45 & 0.712 & 0.436 & 0.827 & 0.81 & 0.79 & 0.7 \\
\hline 43 & - & - & - & 0.1 & - & 0.9 & - & - & 1.42 & 0.728 & 0.468 & 0.833 & 0.82 & 0.805 & 0.7 \\
\hline 44 & - & - & - & 0.2 & - & 0.8 & - & - & 1.37 & 0.761 & 0.533 & 0.847 & 0.84 & 0.834 & 0.8 \\
\hline 45 & - & - & - & 0.3 & - & 0.7 & - & - & 1.33 & 0.793 & 0.598 & 0.861 & 0.86 & 0.861 & 0.8 \\
\hline 46 & - & - & - & 0.4 & - & 0.6 & - & - & 1.28 & 0.826 & 0.664 & 0.876 & 0.88 & 0.886 & 0.8 \\
\hline 47 & - & - & - & 0.5 & - & 0.5 & - & - & 1.23 & 0.859 & 0.729 & 0.893 & 0.9 & 0.908 & 0.9 \\
\hline 48 & - & - & - & 0.6 & - & 0.4 & - & - & 1.18 & 0.892 & 0.794 & 0.911 & 0.92 & 0.929 & 0.9 \\
\hline 49 & - & - & - & 0.7 & - & 0.3 & - & - & 1.13 & 0.924 & 0.859 & 0.93 & 0.94 & 0.949 & 0.9 \\
\hline 50 & - & - & - & 0.8 & - & 0.2 & - & - & 1.08 & 0.957 & 0.924 & 0.952 & 0.96 & 0.967 & 0.9 \\
\hline 51 & - & 0.72 & - & 0.08 & - & - & 0.2 & - & 1.37 & 0.77 & 0.551 & 0.989 & 0.995 & 0.998 & 0.9 \\
\hline 52 & - & 0.48 & - & 0.32 & - & - & 0.2 & - & 1.24 & 0.857 & 0.72 & 0.988 & 0.995 & 0.999 & 0.9 \\
\hline
\end{tabular}


Table 2. Cont'd

\begin{tabular}{|c|c|c|c|c|c|c|c|c|c|c|c|c|c|c|c|}
\hline \multirow[t]{2}{*}{ Mixture } & \multicolumn{8}{|c|}{ Component fractional AOT (at $558 \mathrm{~nm}$ ) } & \multicolumn{3}{|c|}{ AOT rel. to green } & \multicolumn{4}{|c|}{ single-scattering albedo } \\
\hline & $1^{\mathrm{a}}$ & $2^{\mathrm{a}}$ & $3^{\mathrm{a}}$ & $6^{\mathrm{a}}$ & $8^{\mathrm{a}}$ & 14 & $19^{\mathrm{a}}$ & $21^{\mathrm{a}}$ & Blue & Red & Nir & Blue & Green & Red & Nir \\
\hline 53 & - & 0.16 & - & 0.64 & - & - & 0.2 & - & 1.06 & 0.973 & 0.946 & 0.986 & 0.995 & 0.999 & 0.9 \\
\hline 54 & - & 0.54 & - & 0.06 & - & - & 0.4 & - & 1.25 & 0.844 & 0.683 & 0.977 & 0.991 & 0.997 & 0.9 \\
\hline 55 & - & 0.36 & - & 0.24 & - & - & 0.4 & - & 1.15 & 0.909 & 0.81 & 0.975 & 0.991 & 0.997 & 0.9 \\
\hline 56 & - & 0.12 & - & 0.48 & - & - & 0.4 & - & 1.02 & 0.996 & 0.979 & 0.972 & 0.991 & 0.998 & 0.9 \\
\hline 57 & - & 0.36 & - & 0.04 & - & - & 0.6 & - & 1.13 & 0.918 & 0.815 & 0.962 & 0.986 & 0.996 & 0.9 \\
\hline 58 & - & 0.24 & - & 0.16 & - & - & 0.6 & - & 1.07 & 0.961 & 0.9 & 0.959 & 0.986 & 0.996 & 0.9 \\
\hline 59 & - & 0.08 & - & 0.32 & - & - & 0.6 & - & 0.977 & 1.02 & 1.01 & 0.956 & 0.986 & 0.997 & 0.9 \\
\hline 60 & - & 0.18 & - & 0.02 & - & - & 0.8 & - & 1.01 & 0.991 & 0.947 & 0.943 & 0.982 & 0.995 & 0.9 \\
\hline 61 & - & 0.12 & - & 0.08 & - & - & 0.8 & - & 0.98 & 1.01 & 0.989 & 0.941 & 0.982 & 0.995 & 0.9 \\
\hline 62 & - & 0.04 & - & 0.16 & - & - & 0.8 & - & 0.936 & 1.04 & 1.05 & 0.938 & 0.982 & 0.995 & 0.9 \\
\hline 63 & - & 0.4 & - & - & - & - & 0.48 & 0.12 & 1.16 & 0.898 & 0.783 & 0.951 & 0.977 & 0.993 & 0.9 \\
\hline 64 & - & 0.4 & - & - & - & - & 0.36 & 0.24 & 1.18 & 0.892 & 0.78 & 0.94 & 0.968 & 0.99 & 0.9 \\
\hline 65 & - & 0.4 & - & - & - & - & 0.24 & 0.36 & 1.19 & 0.887 & 0.776 & 0.928 & 0.959 & 0.986 & 0.9 \\
\hline 66 & - & 0.4 & - & - & - & - & 0.12 & 0.48 & 1.2 & 0.881 & 0.773 & 0.918 & 0.95 & 0.983 & 0.9 \\
\hline 67 & - & 0.2 & - & - & - & - & 0.64 & 0.16 & 1.04 & 0.977 & 0.928 & 0.927 & 0.97 & 0.991 & 0.9 \\
\hline 68 & - & 0.2 & - & - & - & - & 0.48 & 0.32 & 1.05 & 0.969 & 0.924 & 0.91 & 0.958 & 0.987 & 0.9 \\
\hline 69 & - & 0.2 & - & - & - & - & 0.32 & 0.48 & 1.07 & 0.962 & 0.919 & 0.894 & 0.946 & 0.983 & 0.9 \\
\hline 70 & - & 0.2 & - & - & - & - & 0.16 & 0.64 & 1.08 & 0.954 & 0.914 & 0.879 & 0.934 & 0.979 & 0.9 \\
\hline 71 & - & - & - & - & - & - & 0.8 & 0.2 & 0.914 & 1.06 & 1.07 & 0.896 & 0.962 & 0.99 & 0.9 \\
\hline 72 & - & - & - & - & - & - & 0.6 & 0.4 & 0.933 & 1.05 & 1.07 & 0.873 & 0.947 & 0.985 & 0.9 \\
\hline 73 & - & - & - & - & - & - & 0.4 & 0.6 & 0.951 & 1.04 & 1.06 & 0.851 & 0.932 & 0.98 & 0.9 \\
\hline 74 & - & - & - & - & - & - & 0.2 & 0.8 & 0.97 & 1.03 & 1.06 & 0.83 & 0.917 & 0.976 & 0.9 \\
\hline
\end{tabular}

${ }^{\mathrm{a}}$ The eight components used in this mixture table are described in Table 1.
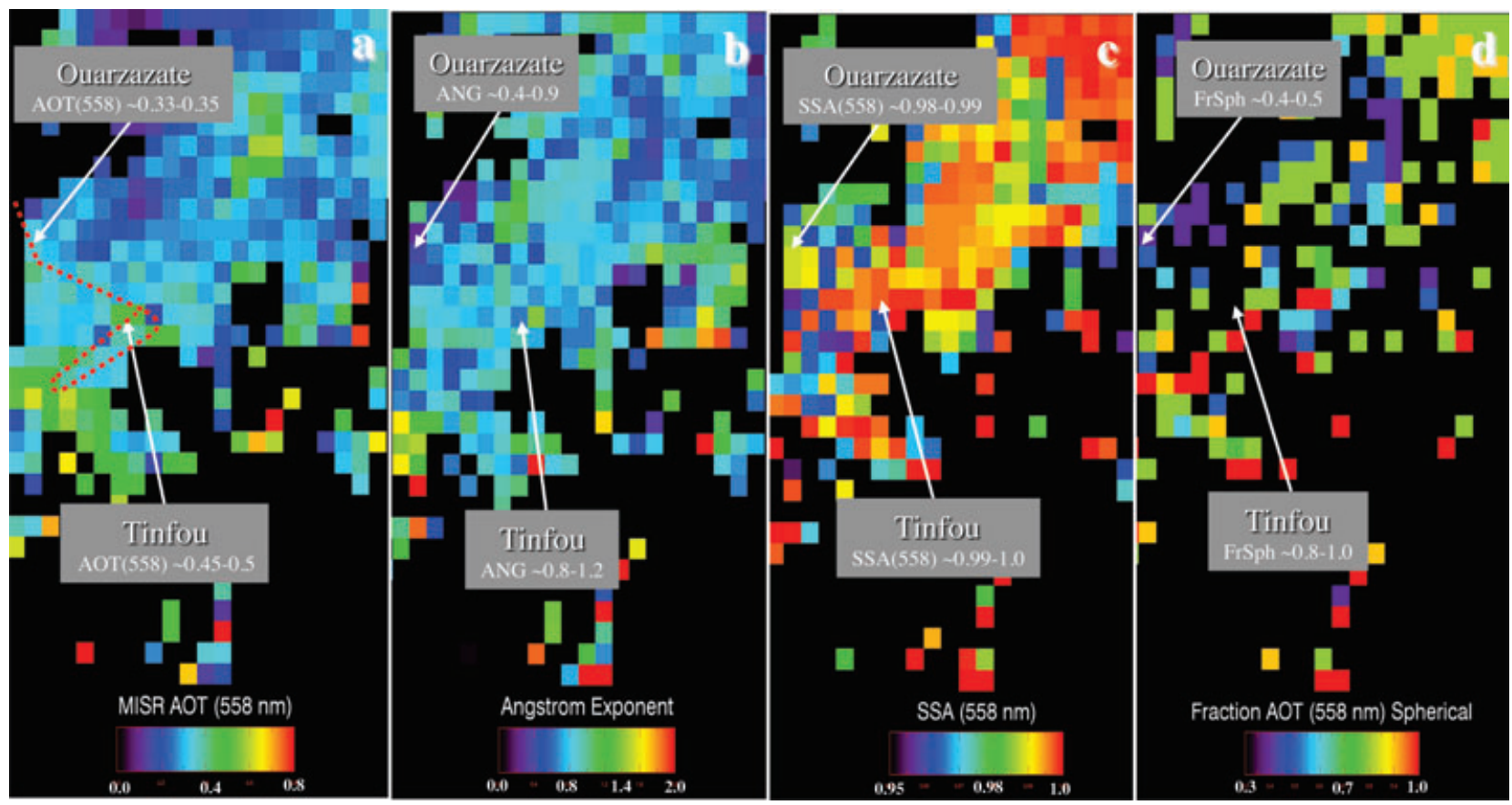

Fig. 4. Same as Fig. 2, but for the 28 May 2006 SAMUM event. 

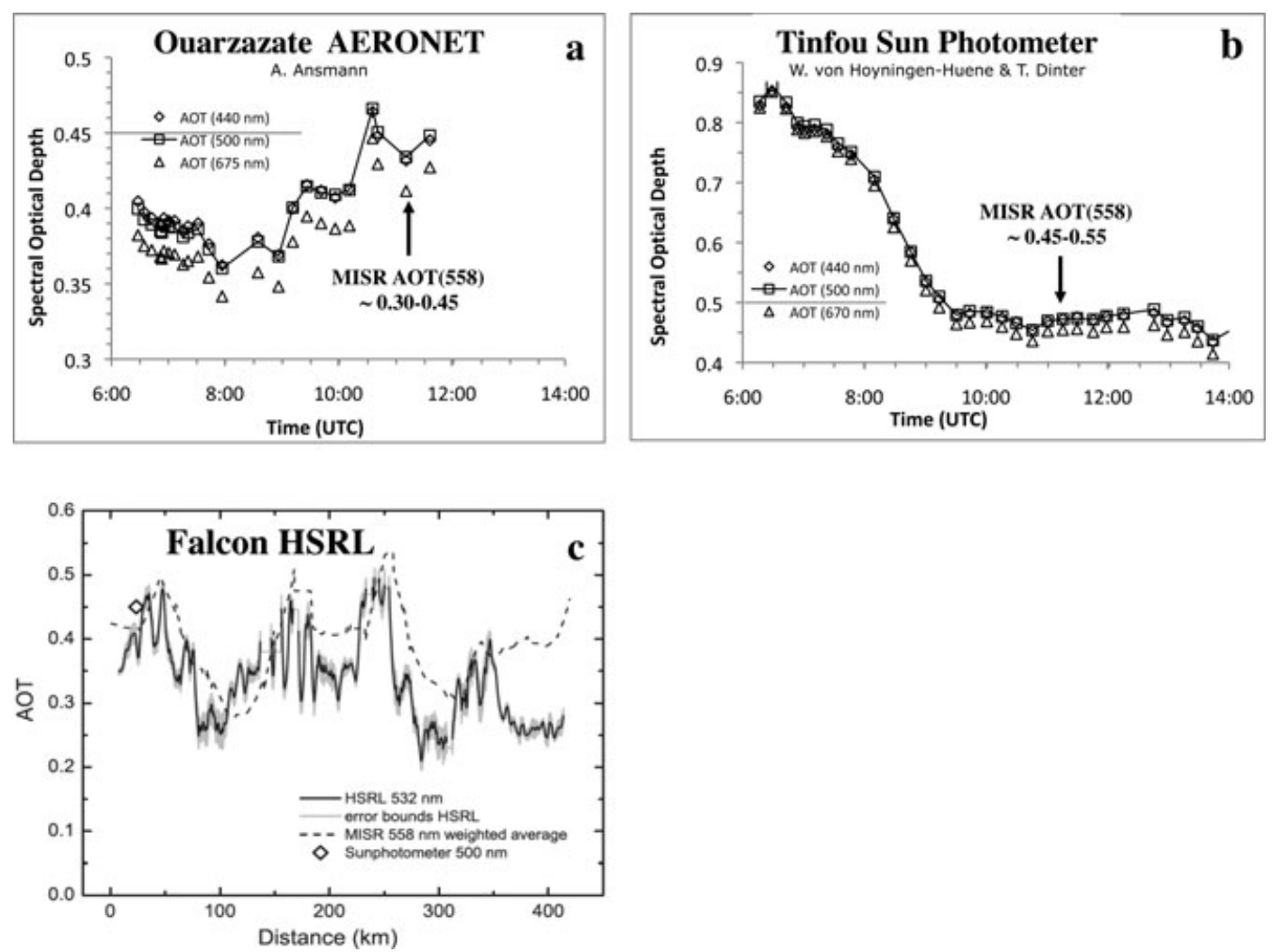

Fig. 5. The 4 June 2006 SAMUM event, Orbit 34369, Path 201. Surface-based sun photometer multispectral AOT time-series at (a) Ouarzazate and (b) Tinfou. The sun photometer green-band AOT at MISR overpass time (11:11 UTC) is indicated with an arrow. (c) Near-coincident, mid-visible AOT derived from the Falcon HSRL on RF-8 (from Esselborn et al., 2008b, fig. 8b), along a trajectory marked approximately as a dashed red line in Fig. 6b, with the spatially correlated MISR AOT and Ouarzazate sun photometer AOT superposed.

between 9 and $11 \mathrm{~km}$ a.s.l. on this day (Fig. 3d). The POLIS total column AOT estimate is 0.431 at $355 \mathrm{~nm}$, of which about 0.09 is attributed to cirrus above $9 \mathrm{~km}$; since cirrus are large particles, this amounts to about 0.08 optical depth when extrapolated to mid-visible wavelengths, and accounts quantitatively for most or all the reported discrepancy between MISR and the Falcon HSRL. The satellite cloud masks are reliably sensitive to clouds having AOT greater than about 0.3 , and in this case, the thinner cloud was apparently not screened out. Identifying and retrieving thin cirrus in the satellite aerosol algorithm, as a large nonspherical, non-absorbing particle, is currently under study.

Returning to Fig. 4a, AOT is more variable in the region immediately surrounding the two surface sites than it was on 19 May, and what appear to be local sources show up as patches of higher AOT one or two $17.6 \mathrm{~km}$ retrieval regions in size, in both the plains south of Ouarzazate and the Zagora basin farther east. On the $\sim 100 \mathrm{~km}$ scale, a weak gradient in retrieved particle properties is observed, with somewhat lower Ångström exponent, higher SSA, and no clear trend in fraction AOT spherical, extending at least $200 \mathrm{~km}$ to the NE from Tinfou.

Based on HYSPLIT backtrajectories (not shown, but see a similar trajectory analysis, performed with a different model, given by Schladitz et al. 2008, fig. 8c), Ouarzazate and Tinfou are in the same regional air flow at all levels; the near-surface $(0.5 \mathrm{~km})$ air comes due west from central Algeria, whereas the mid-level $(1.5 \mathrm{~km})$ flow is due north from western Algeria, and the upper level $(2.5 \mathrm{~km})$ air is advected from the western Sahara, through Mauritania, Mali and Algeria into western Morocco. The similarity of regional wind patterns at the ground stations supports the idea that the observed AOT gradient between Ouarzazate and Tinfou is due to one or more local sources near Tinfou rather than regional-scale activity, though orographic blocking or other topographic effects not reproduced on the scale of the model backtrajectories could also be contributing to the observed differences.

As on 19 May, MISR particle property retrievals favour the $\sim 60 \%$ dust + fine-mode spherical mixtures available in the algorithm (especially Mixtures 55, 57, 58 and 63 in Table 2), and again results at Ouarzazate are more tightly constrained than those in the Zagora region. The 28 May event falls during Period 2 of the SAMUM campaign; detailed analysis shows hardly any aerosol compositional differences compared to Period 1 (which included 19 May; Petzold et al., 2008; Schladitz et al., 2008). As expected, MISR-retrieved aerosol 

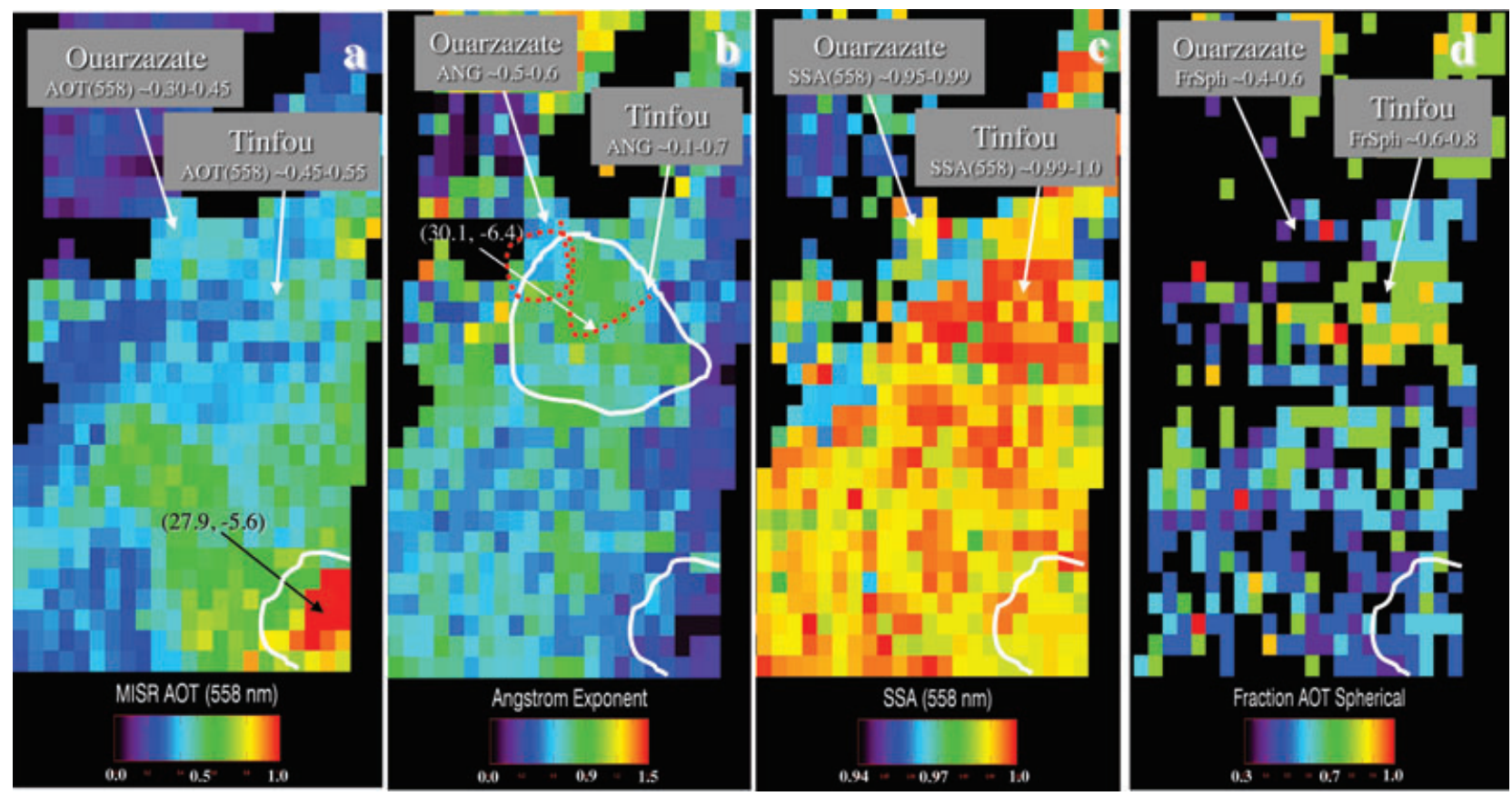

Fig. 6. Same as Fig. 2, but for the 4 June 2006 SAMUM event. The locations of a likely dust storm SSE of the prime study region and an apparent concentration of small, bright, spherical particles are marked in white, and the central latitudes and longitudes are given in parentheses. The trajectory of the Falcon HSRL is marked approximately as a dashed red line in part (b), and asterisks mark the later segment of the flight, between Ouarzazate and Tinfou.

microphysical properties over the study region for these two events are indistinguishable.

\subsection{June 2006}

Mid-visible AOT for 4 June follows a pattern similar to the other days, with values around 0.5 , and Tinfou slightly higher than Ouarzazate at MISR overpass time (Fig. 5), even though on this day, AOT over Tinfou decreases during the morning hours prior to overpass (Fig. 5b). Similarly, the MISR-HSRL AOT comparison in Fig. 5c shows agreement similar to previous days, except at the very end of the Falcon flight, near Tinfou, roughly $20 \mathrm{~min}$ after the MISR overpass (The MISR AOT map in Fig. 6a reveals an AOT increase in excess of 0.1 just east of Tinfou, and a combination of aerosol advection and data set co-location differences amounting to one $17.6 \mathrm{~km}$ MISR aerosol retrieval region can account for the observed discrepancy). Particle property retrieval results at the two prime study sites also reproduce those of the previous Golden Days.

But the regional view in Fig. 6 reveals several new features of interest. A high AOT region of large, bright, primarily nonspherical particles appears about $300 \mathrm{~km}$ south of Tinfou. This we identify as a dust storm. The dust is likely the remnant of a plume created on the previous day by a large density current that formed along the slopes of the High Atlas mountains, as precipitation evaporated above the ground, cooling the associated air mass (Knippertz et al., 2007, fig. 10b). The front passed
Tinfou in the early morning hours of 4 June, and by MISR overpass time (11:11 UTC), at the estimated speed of $\sim 8 \mathrm{~m} \mathrm{~s}^{-1}$, it would have travelled between about 200 and $300 \mathrm{~km}$ farther south, to the approximate location of the feature observed in Fig. 6. Other satellite observations also show the edge of an airborne dust cloud near the MISR-observed location, though at different times during this day (Heinold et al., 2008, Fig. 2, column 3). In general, geostationary instruments such as the Meteosat imager are far more effective at tracking the motions of such storms (e.g. Knippertz et al., 2007) than snapshots from relatively narrow-swath instruments on polar orbiting satellites, but MISR does provide additional information: at its thickest, the mid-visible AOT in the observed part of the plume is close to 1.3 , and roughly $50 \%$ of this is attributed to non-spherical particles.

A more subtle feature appears to the south and east of Ouarzazate, just south and west of Tinfou, that seems to be a relative enhancement of small-medium, spherical, very bright particles (outlined in Fig. 6b). This may simply be a region of reduced dust concentration, as the total column AOT is $\sim 0.35$, compared to about 0.5 for the lower SSA, lower Ångström exponent areas to the south and east. The fraction AOT spherical within the feature is about 0.8, whereas in the surroundings, it is near 0.5, implying a spherical particle AOT of 0.28 and 0.25 , respectively. This represents only a marginally higher column abundance of small particles, at the limit of MISR detectability for such relative distinctions. However, it seems to yield consistent particle 
Fig. 7. (a) Falcon HSRL 536/1064 nm colour ratio for the segment of the 4 June flight between Ouarzazate and Tinfou, marked with asterisks along the aircraft trajectory in Fig. 6b. (b) Three-day backtrajectories for the 4 June 2006 SAMUM event, evaluated at $0.6,1.8$ and $3.3 \mathrm{~km}$ above the terrain (approximately 1.8 , 3 and $4.5 \mathrm{~km}$ a.s.1.) from the HYSPLIT model (Draxler and Rolph, 2003) for (1) Ouarzazate, (2) Tinfou and (3) near the centre of the small, bright, spherical particle concentration of Fig. 6.
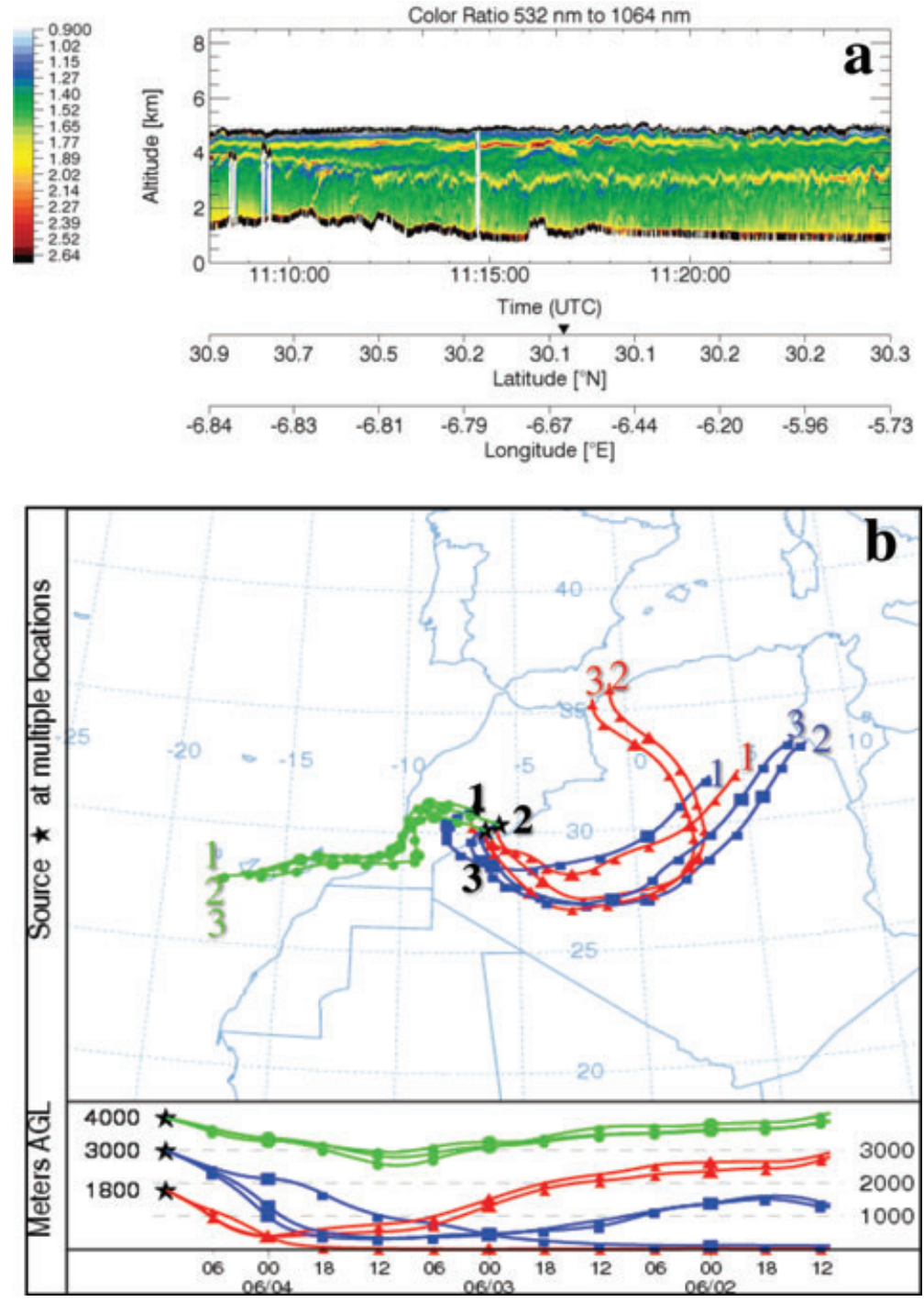

property retrieval results over a region approximately $200 \mathrm{~km}$ in extent.

Sahara mineral dust experiment field measurements shed some light on the likely interpretation of this MISR feature. Particle size distributions measured in situ between 10:24 and 10:31 UTC over Ouarzazate show a markedly enhanced finemode aerosol concentration at $1.9 \mathrm{~km}$ a.s.l. (Heinold et al., 2008, fig. 9e). The airborne HSRL finds backscatter peaks in the region between 2.5 and $3.5 \mathrm{~km}$, identified as dust, and additional peaks between 1.5 and $2 \mathrm{~km}$, and around $4 \mathrm{~km}$ a.s.l. (Esselborn et al., 2008b). Most significantly, the final leg of the Falcon research flight that day covered an ' $L$ ' pattern between Ouarzazate and Tinfou that penetrated the heart of the MISR feature (Fig. 6b). The lidar colour ratio for this segment is reproduced in Fig. 7a; it identifies two very thin aerosol layers, at approximately 3.0 and $4.5 \mathrm{~km}$ a.s.1. having high colour ratios, indicative of small particles. The lidar backscatter-to-extinction ratios on this day were also generally lower than those for the 19 and 28 May flights (Esselborn et al., 2008b, fig. 6), suggesting the presence of a higher fraction of particles having non-dust composition.

Three-day HYSPLIT backtrajectories for the two prime study sites and a location near the centre of the small-particle feature, evaluated at about the peaks of the layers observed by the airborne HSRL, are plotted in Fig. 7b. Of these, the trajectories culminating at $1.8 \mathrm{~km}$ a.s.l. above the MISR feature location and over Tinfou cross population centres in northern Algeria from which layers of small, spherical aerosol pollution particles could have originated. But the evidence in this case is only circumstantial. The challenge of obtaining strong validation data over parts of the MISR swath away from the immediate study region illustrates the complementary nature of satellite and suborbital data. It also highlights the value of assessing MISR aerosol retrieval quality, where possible, through field campaigns such as SAMUM, since the validated satellite observations can then be 
used to map aerosol air masses and regional AOT gradients, as demonstrated by these examples.

\section{Summary and conclusions}

This paper takes the initial steps toward validating MISR's ability to retrieve aerosol optical and microphysical properties of desert dust and related aerosol air mass types over bright desert surfaces, using near-coincident field data acquired during the SAMUM campaign of 2006. It also provides regional maps of aerosol amount and properties derived with the MISR standard aerosol algorithm (Version 19).

Multi-angle imaging spectroradiometer mid-visible AOT agrees point-by-point with available validation data within $0.05-$ 0.1 , about as well as can be expected when AOT space-time variability, and the spatial sampling differences between the field and satellite instruments, are taken into account. The satellite observations capture AOT trends and variability over extended regions, providing context for more detailed suborbital measurements.

The field data are also used to probe the limits of MISR's ability to distinguish and to map aerosol air masses, from the combination of retrieved constraints on particle size, shape and SSA. For the three SAMUM Golden Days, 19 and 28 May and 4 June 2006, the satellite observations highlight regional gradients in the mix of dust and background spherical particles, identify a dust plume that is most likely part of a density flow, and show an aerosol air mass containing a higher proportion than the surroundings of small, spherical particles. This appears to be aerosol pollution transported from several thousand kilometres away.

Aggregating particle properties into aerosol air mass types offers a more robust quantity than do the retrieved particle microphysical properties (size, shape and SSA) individually. We identified a lack of small, spherical, absorbing particles in the MISR algorithm's complement of bi-modal mixtures containing mineral dust, and found evidence supporting earlier indications that the spheroidal coarse-mode dust optical model currently used is not optimal for multi-angle retrievals. The comparisons with field data also illustrated the known impacts of complex topography and thin, uniform cirrus on the MISR retrievals. A next step in refining the MISR aerosol algorithm and assessing its quality involves exploring quantitatively the ranges of aerosol components and mixtures to which MISR is sensitive, using cases where the answer is known from direct measurements. This is one value of the SAMUM Golden Day observations, and is the subject of continuing work.

The MISR data set for the SAMUM campaign is available through a dedicated web site at the NASA Langley Atmospheric Sciences Data Center:

http://eosweb.larc.nasa.gov/PRODOCS/misr/samum/table_ samum.html

\section{Acknowledgments}

We thank our colleagues of the Jet Propulsion Laboratory's MISR instrument team and at the NASA Langley Research Center's Atmospheric Sciences Data Center for their roles in producing the MISR data sets and A. Ansmann for supporting the Ouarzazate AERONET station. R. Kahn thanks Jost Heintzenberg and colleagues for the invitation to participate in the SAMUM campaign, and the SAMUM Research Community for their hospitality. The work of R. Kahn is supported in part by NASA's Climate and Radiation Research and Analysis Program, under H. Maring, NASA's Atmospheric Composition Program under R. Halthore, and the EOS-MISR instrument project.

\section{References}

Abdou, W. A., Diner, D. J., Martonchik, J. V., Bruegge, C. J., Kahn, R. A. and co-authors. 2005. Comparison of coincident MISR and MODIS aerosol optical depths over land and ocean scenes containing AERONET sites. J. Geophys. Res. 102, doi:10.1029/2004JD004693.

Ansmann, A., Tesche, M., Knippertz, P., Bierwirth, E., Althausen, D. and co-authors. 2008. Vertical profiling of convective dust plumes in southern Morocco during SAMUM. Vertical profiling of convective dust plumes in southern Morocco during SAMUM. Tellus 61B, doi:10.1111/j.1600-0889.2008.00384.x.

Chen, W.-T., Kahn, R., Li, W.-H. and Seinfeld, J. 2008. Sensitivity of multi-angle imaging to optical and microphysical properties of biomass burning particles. J. Geophys. Res. 113, D10203, doi:10.1029/2007JD009372.

Diner, D. J., Beckert, J. C., Reilly, T. H., Bruegge, C. J., Conel, J. E. and co-authors. 1998. Multiangle Imaging SptectrRadiometer (MISR) description and experiment overview, IEEE Trans. Geosci. Remote Sens. 36, 1072-1087.

Dinter, T., von Hoyningen-Huene, W., Burrows, J. P., Kokhanovsky, A., Bierwirth, E. and co-authors. 2008. Retrieval of aerosol optical thickness for desert conditions using MERIS observations during the SAMUM campaign. Tellus 61B, doi:10.1111/j.1600-0889.2008.00391.x.

Draxler, R. R. and Rolph G. D. 2003. HYSPLIT (HYbrid Single-Particle Lagrangian Integrated Trajectory) Model access via the NOAA ARL READY Website, NOAA Air Resour. Lab., Silver Spring, Md. available at: http://www.arl.noaa.gov/ready/hysplit4.html.

Esselborn, M., Wirth, M. Fix, A., Tesche, M. and Ehret, G. 2008a. Airborne high spectral resolution lidar formeasuring aerosol extinction and backscatter coefficients. Appl. Opt. 47, 346-358.

Esselborn, M., Wirth, M., Fix, A., Weinzierl, B., Rasp, K. and co-authors. 2008b. Spatial distribution and optical properties of Saharan dust observed by airborne high spectral resolution lidar during SAMUM 2006. Tellus 61B, doi:10.1111/j.1600-0889.2008.00394.x.

Heinold, B., Tegen, I., Knippertz, P., Laurent, B., Schepanski, K. and coauthors. 2008. Regional Saharan dust modeling during the SAMUM 2006 campaign. Tellus 61B, doi:10.1111/j.1600-0889.2008.00387.x.

Heintzenberg, J. 2008. The SAMUM-1 experiment over Southern Morocco: overview and introduction. Tellus 61B, doi:10.1111/j.16000889.2008.00403.x.

Holben, B. N., Eck, T. F., Slutsker, I., Tanre, D., Buis, J. P. and coauthors. 1998. AERONET — a federated instrument network and data 
archive for aerosol characterization. Remote Sens. Environ. 66, 116.

von Hoyningen-Huene, W., Dinter, T., Kakhanovsky, A. A., Burrows, J. P. and Diouri, M. 2008. Measurements of desert dust optical characteristic at Porte au Sahara during SAMUM. Tellus 61B, doi:10.1111/j.1600-0889.2008.00405.x.

Kahn, R., West, R., McDonald, D., Rheingans, B., and Mishchenko, M. I. 1997. Sensitivity of multi-angle remote sensing observations to aerosol sphericity. J. Geophys. Res. 102, 16 861-16 870.

Kahn, R., Banerjee, P., McDonald, D. and Diner, D. 1998. Sensitivity of multiangle imaging to aerosol optical depth, and to pure-particle size distribution and composition over ocean. J. Geophys. Res. 103, 32 195-32 213.

Kahn, R., Banerjee, P. and McDonald, D. 2001. The sensitivity of multiangle imaging to natural mixtures of aerosols over ocean. J. Geophys. Res. 106, 18 219-18 238.

Kahn, R., Gaitley, B., Martonchik, J., Diner, D., Crean, K. and coauthors. 2005. MISR global aerosol optical depth validation based on two years of coincident AERONET observations. J. Geophys. Res. 110, doi:10:1029/2004JD004706.

Kalashnikova, O. V. and Kahn, R. A. 2006. The ability of multi-angle remote sensing observations to identify and distinguish mineral dust types, part 2: sensitivity data analysis. J. Geophys. Res. 111, D11207, doi:10.1029/2005JD006756.

Kalashnikova, O. V., Kahn, R., Sokolik, I. N. and Li, W.-H. 2005. The ability of multi-angle remote sensing observations to identify and distinguish mineral dust types, part 1: optical models and retrievals of optically thick plumes. J. Geophys. Res. 110, doi:10.1029/2004JD004550.

Knippertz, P., Deutscher, C., Kandler, K., Müller, T., Schulz, O. and co-authors. 2007. Dust mobilization due to density currents in the Atlas region: observations from the SAMUM 2006 field campaign. $J$. Geophys. Res. 112, doi:10.1029/2007JD008774.
Knippertz, P., Ansmann, A., Althausen, D., Müller, D., Tesche, M. and co-authors. 2008. Dust mobilization and transport in the northern Sahara during SAMUM 2006-a meteorological overview. Tellus 61B, doi:10.1111/j.1600-0889.2008.00380.x.

Martonchik, J. V., Diner, D. J., Kahn, R., Verstraete, M. M., Pinty, B. and co-authors. 1998. Techniques for the retrieval of aerosol properties over land ocean using multiangle data. IEEE Trans. Geosci. Remote Sens. 36, 1212-1227.

Martonchik, J. V., Diner, D. J., Crean, K. A. and Bull, M. A. 2002. Regional aerosol retrieval results From MISR. IEEE Trans. Geosci. Remote Sens. 40, 1520-1531.

Martonchik, J. V., Diner, D. J., Kahn, R. A., Gaitley, B. J. and Holben, B. N. 2004. Comparison of MISR and AERONET aerosol optical depths over desert sites. Geophys. Res. Lett. 31, doi:10.1029/2004GL019807.

Otto, S., Bierwirth, E., Weinzieri, B., Kandler, K., Esselborn, M. and coauthors. 2008. Solar radiative effects of a Saharan dust plume observed during SAMUM assuming spheroidal model particles. Tellus 61B, doi:10.1111/j.1600-0889.2008.00389.x.

Petzold, A., Rasp, K., Weinzierl, B., Esselborn, M., Hamburger, T. and co-authors. 2008. Saharan dust refractive index and optical properties from aircraft-based observations during SAMUM 2006. Tellus 61B, doi:10.1111/j.1600-0889.2008.00383.x.

Prospero, J. M., Glaccum, R. A. and Nees, R. T. 1981. Atmospheric transport of soil dust from Africa to South America. Nature 298, $570-572$.

Schladitz, A., Müller, T., Massling, A., Kaaden, N., Kandler, K. and co-authors. 2008. In situ measurements of optical properties at Tinfou (Morocco) during the Saharan Mineral Dust Experiment SAMUM 2006. Tellus 61B, doi:10.1111/j.1600-0889.2008.00397.x.

Schepanski, K., Tegen, I., Laurent, B., Heinold, B. and Macke, A. 2007. A new Saharan dust source activation frequency map derived from MSG-SEVIRI IR channels. Geophys. Res. Lett. 34, L18803, doi:10.1029/2007GL030168. 